\title{
A CAPOEIRA NA FORMAÇÃO DOCENTE DE EDUCAÇÃO FÍSICA
}

\section{Gilbert de Oliveira Santos}

Universidade Federal dos Vales do Jequitinhonha e Mucuri, Diamantina, Minas Gerais, Brasil

\section{Leandro Ribeiro Palhares}

Universidade Federal dos Vales do Jequitinhonha e Mucuri, Diamantina, Minas Gerais, Brasil

\begin{abstract}
Resumo
Este trabalho tem como objetivo apresentar algumas reflexões a respeito da inclusão da capoeira na formação de professores de educação física. A partir de referenciais teóricos da área procuramos apresentar algumas sugestões para o processo de pedagogização da capoeira. Consideramos que ainda há muito por fazer em relação à incorporação da capoeira no âmbito da educação física, por isso, nossa intenção foi apresentar algumas reflexões e sugestões pedagógicas que possam contribuir neste processo.
\end{abstract}

Palavras-chave: Capoeira - Formação de Professores - Pedagogização

\section{Introdução}

Gaz parte do estatuto da Educação Física lidar com práticas corpo1 rais. Práticas históricas que expressam sentidos e significados e que constituem um acervo de conhecimentos a ser considerado no processo de formação docente em Educação Física. Baseando-se no Coletivo de Autores (1992), podemos chamar esse acervo de conhecimentos de cultura corporal e a Educação Física como uma área de estudo desse conhecimento.

Dentre os diversos conhecimentos que compõem a cultura corporal e que, portanto, devem ser abordados na formação de professores, temos a capoeira, prática corporal de origem afro-brasileira ${ }^{1}$. Portanto, a capoeira constitui um conhecimento a ser estudado por docentes de Educação Física, pois os mesmos possuem a responsabilidade e o de-

1-“(...) a capoeira é Afro-Brasileira, ela não veio da África! Ela nasceu no Brasil, ela é nascida no Brasil de filhos de pais africanos. Esses africanos trouxeram para cá o legado da África, que foi aqui transformado". (Depoimento de Carlos Eugênio Líbano Soares em: MESTRE BIMBA, 2006, dvd). 
safio de ensinar este legado da humanidade no âmbito escolar e, além disso, a capoeira vem se tornando presente nos currículos formais como conhecimento da Educação Física escolar e através de projetos sociais na escola (SOUZA; OLIVEIRA, 2001; JÚNIOR; ABIB; SOBRINHO, 2000). Também no ensino superior, fomenta-se a capoeira através de disciplinas e projetos de extensão nos cursos de Educação Física (CAMPOS, 2000; CAVALCANTE; PALHARES, 2008).

Mas também é importante reconhecer que há outros profissionais que lidam legitimamente com esta prática social. É importante respeitar esses profissionais de outras áreas, pois há muitas maneiras de lidar e pensar o corpo e as práticas corporais. A Educação Física é uma área que estuda essas maneiras, mas não lhe é direito o monopólio dos saberes e das práticas corporais. Neste sentido, pode haver certo conflito que surgiria do embate entre a legitimidade do mestre de capoeira como portador e elo principal de acesso aos saberes de uma prática cujas raízes surgem de um ambiente não formal de ensino e da legalidade do professor de Educação Física cuja responsabilidade é sistematizar o ensino dos saberes da cultura corporal na escola, inclusive da capoeira. Cabe aqui a transcrição do depoimento de um renomado mestre da capoeiragem baiana, Mestre Curió, que exemplifica o embate acima descrito:

Quando eu fui num debate e eles disseram que o camarada para ensinar uma capoeira na universidade tinha que ter um curso de professor de educação física e tinha que ser universitário. E eu debati! Por que eles dizem que eu sou analfabeto! Eu sou analfabeto pode ser na leitura, mas na capoeira! Quando vir discutir comigo se segure, por que eu não ando com o livro na mão não! O livro apaga e aqui não! (apontando para a cabeça). Só apaga quando eu morrer. Por que eu tenho aqui dentro da mente (Depoimento de Mestre Curió em: PASTINHA, 1998, dvd).

Ao tratar dos mestres de capoeira nos referimos àqueles que desenvolvem seu trabalho com respeito aos fundamentos e tradição, valorizando a história e os mestres ancestrais e, principalmente, que não abrem mão de principiar sua prática e conduta pela preservação, valorização e disseminação da capoeira em detrimento das facilidades financeiras e sociais que dela possam usufruir.

Há muitas maneiras de ensinar e os mestres de capoeira, apesar de 
não possuírem diplomas ou licença para lecionar em universidades ou outras instituições, são notórios na arte de ensinar a capoeira, além de serem os principais responsáveis pela preservação, disseminação e consequente sobrevivência dessa atividade:

O mestre é aquele que é reconhecido por sua comunidade, como o detentor de um saber que encarna as lutas e sofrimentos, alegrias e celebrações, derrotas e vitórias, orgulho e heroísmo das gerações passadas, e tem a missão quase religiosa de disponibilizar esse saber àqueles que a ele recorrem. O mestre corporifica, assim, a ancestralidade e a história de seu povo e assume, por essa razão, a função do poeta que, através do seu canto, é capaz de restituir esse passado como força instauradora, que irrompe para dignificar o presente e conduzir a ação construtiva do futuro. (ABIB, 2006, p.92).

Não pretendemos realizar aqui nenhum tipo de comparação entre campos $^{2}$ diferentes que lidam com a capoeira. Nosso recorte de reflexão opta por apresentar algumas reflexões sobre a formação de professores de Educação Física no que tange ao conhecimento capoeira a partir do nosso lugar ${ }^{3}$ de análise que se localiza fundamentalmente no

2-Segundo Paiva (2005) campo, na perspectiva de Pierre Bourdie, significa: “(...) um espaço de jogo social concorrencial que implica relações de força e monopólios a serem estabelecidos, defendidos, quebrados, em luta simbólica, e suas estratégias, na defesa de interesses e lucros que proporcionem acúmulo de capital simbólico, decorrentes de relações objetivas entre posições, disposições e predisposições adquiridas no campo e que nele podem ser objetivadas." (PAIVA, 2005, p.02).

3-Mesmo não se tratando de uma pesquisa historiográfica, o conceito de lugar do historiador Michel de Certeau nos lembra que na pesquisa é importante assumir os limites e possibilidades do contexto em que se está inserido. Assumir que o objeto de análise não existe sem a interpretação do sujeito e que o sujeito está enraizado em um lugar de produção socioeconômica, política e cultural que implica: "um meio de elaboração que é circunscrito por determinações próprias: uma profissão liberal, um posto de observação ou de ensino, uma categoria de letrados, etc. Ela está, pois, submetida a imposições, ligada a privilégios, enraizada em uma particularidade. É em função deste lugar que se instauram os métodos, que se delineia uma topografia de interesses, que os documentos e as questões, que lhes serão propostas, se organizam." (CERTEAU, 1982, p.66-67). 
campo da Educação Física, o que também não quer dizer que se trata de um lugar de observação melhor ou pior que outros.

\section{A capoeira e a formação de professores de Educação Física}

Estudando o trato das lutas nos cursos de formação, Alves Júnior (2006) aponta que a esportivização ainda é o elemento balizador do trato das lutas nas disciplinas ligadas a este tema:

Durante muitos anos o ensino das lutas esteve restrito ao que se fazia nas instituições militares, nos clubes ou academias e neste caso quem dirigia os considerados treinamentos, na grande maioria das vezes não se constituía de professores de educação física e quando isto ocorria, não havia muita diferença entre o que era proposto, pois o formato competitivo ou de defesa pessoal falavam mais alto. $\mathrm{O}$ modelo esportivizado tendo as competições oficiais como parâmetros de regras a serem seguidas, ainda é uma realidade encontrada em determinados estabelecimentos de formação de professores de educação física... (ALVES JÚNIOR, 2006, p.06).

De fato, uma das dificuldades da inserção da capoeira nos cursos de formação superior de professores de Educação Física diz respeito ao tratamento pedagógico dado a este conhecimento, ou seja, como ensinar a capoeira.

Acreditamos que ao tematizar a capoeira, o professor de Educação Física precisaria lidar com esse conhecimento de maneira particular e diferente do que ocorre no campo específico da capoeira, que é notadamente formado pelos grupos ${ }^{4}$.

Ensinar é um ato de descoberta e de liberdade, portanto, assim como não é preciso (e nem viável) ser professor de Educação Física para ser um mestre ${ }^{5}$ de capoeira, então um docente com essa formação não

4-Os grupos de capoeira são a maneira preponderante de organizar os sujeitos em torno da prática. Há muitos grupos de capoeira, assim como também há diferentes formas deles se constituírem. Desde grupos pequenos em que as relações se estabelecem em torno de um único mestre até grupos transnacionais, com grande número de adeptos e mestres de capoeira.

5-O mestre possui grande representatividade e particularidade no campo da capoeira. Ele é o eixo principal de todo processo de transmissão dos saberes. Para saber 
precisa (e nem deve) ser um mestre para ensinar capoeira na escola. Portanto, se a atuação docente em Educação Física é diferente da atuação de um mestre de capoeira, logo, nos cursos de formação superior de docentes a abordagem dada ao conhecimento da capoeira também deve ser diferente. Mas como inserir a capoeira no âmbito da formação de docentes de Educação Física?

Um parâmetro que nos baliza é que não é necessário formar professores que dominem as técnicas da capoeira e/ou tenham uma compreensão profunda da mesma, até mesmo porque se trata de um curso de licenciatura em Educação Física e não de capoeira. Logo, os docentes devem ter uma compreensão do papel social da capoeira condizente e orientada para o campo de atuação em escolas. Isso não quer dizer que seja um conhecimento inferior ou superior ao do mestre de capoeira. Ambos são conhecimentos de ordem epistemológica e pedagógica diferentes e que, portanto, atendem a objetivos diferentes, mesmo ocorrendo dentro do mesmo lugar: a escola.

A capoeira na escola como um projeto extracurricular, ou seja, como aula a parte no contra turno letivo, pode ter objetivos semelhantes aos dos espaços específicos de capoeira. Neste caso, o mestre de capoeira é a pessoa mais indicada para este ensino. Já a capoeira na escola como conteúdo da Educação Física escolar deve se adequar ao projeto pedagógico da escola, e neste caso, é o professor de Educação Física o profissional respaldado para ensinar.

Para Brasil (1998) e Darido e Rangel (2005), os conteúdos das aulas de Educação Física escolar devem ser abrangidos em três dimensões: conceitual (o que se deve saber), procedimental (o que se deve saber fazer) e atitudinal (como se deve ser). A capoeira como conhecimento da Educação Física escolar também deve se remeter a estas dimensões. Um exemplo é a roda de capoeira, reunião em círculo onde os componentes se dividem e revezam as funções: tocar os instrumentos, cantar, bater palmas, responder o coro e o jogar. A prática corporal, ou seja, o jogo da capoeira ou tocar os instrumentos é a dimensão procedimental (saber fazer); aprender a reconhecer a importância de todas as pessoas e funções, compreendendo que sem uma delas a roda não se constitui plenamente é a dimensão atitudinal (aquisição de valores para a vida); e contextualizar o porquê da forma circular da roda,

mais sobre as particularidades do processo de ensino da capoeira centrado no mestre sugerimos Abib (2006) e Santos (2005). 
a inserção da musicalidade na capoeira ou a história da capoeira é a dimensão conceitual (saber sobre o que se está fazendo).

Mas como propor alguns princípios pedagógicos para a capoeira nos cursos de formação superior sem cair na armadilha de cristalizar a capacidade dos professores com receitas prontas de aulas? Nossa tentativa será apresentar princípios que sistematizam minimamente o que o corpo, objeto de compreensão e atuação do professor de Educação Física, pode dizer e ser como conhecimento através da capoeira. Essa ideia de pensar sentidos e significados importantes da capoeira exige do leitor tentar transformar estes sentidos e significados expressos em palavras em práticas corporais, ou seja, em um saber-fazer corporal ${ }^{6}$. Assim, optamos por apresentar alguns princípios pedagógicos que consideramos fundamentais para a experimentação corporal da capoeira. O que não quer dizer que não haja outros princípios ou outras formas de compreender, refletir e se apropriar do saber-fazer da capoeira. Nossa expectativa é tentar abranger alguns princípios gerais que entendemos como essenciais a serem considerados em um contexto de formação de professores de Educação Física, que vão se apropriar desses princípios para compor suas aulas na Educação Física escolar.

Assim, a ideia de apresentar sete princípios gerais da capoeira (caráter combativo, dissimulação/disfarce, inversão corporal, musicalidade, diálogo corporal, raiz africana e mandinga) é para o docente de Educação Física conhecer e compreender outras possibilidades da capoeira e, com a contribuição destes princípios, tornar possível a utilização de elementos da capoeira na elaboração das aulas de Educação Física escolar.

\section{Alguns princípios da capoeira}

\section{Caráter Combativo}

A capoeira, ao longo do tempo, configurou-se como uma forma de identidade do negro em nossa sociedade. Os escravos a criaram como um recurso de afirmação étnica e de luta pela vida. Naquele momento,

6-Nas palavras de Betti (1994, p. 42): "Este é um saber que não pode ser alcançado pelo puro pensamento; é um saber orgânico, só possível com as atividades corporais, não é um saber que se esgota num discurso sobre o corpo/movimento. O papel do profissional da educação física é ajudar a fazer a mediação deste saber orgânico para a consciência, através da linguagem e dos signos". 
o corpo insurgiu-se, expressou seu inconformismo àquele sistema que coibia sua liberdade. Desde então, a capoeira nos mostra uma possibilidade de embate corporal e nesse sentido ela apresenta-se como uma luta. Então, o caráter combativo da capoeira precisa ser vivenciado corporalmente, é preciso propor, no processo de ensino e aprendizagem, práticas que simulem um combate através de gestos, ou seja, os golpes da capoeira. Mas também é importante distinguir luta de bri$\mathrm{ga}^{7}$, pois a ideia de uma agressão, física ou moral, intencional e descontextualizada de significados e sentidos não tem fins pedagógicos, logo não cabe em um processo formal de ensino.

\section{Dissimulação/Disfarce}

A capoeira pode ser considerada uma prática corporal integrante ao contexto das lutas, entretanto, não é consensual que a capoeira deva ser abordada unicamente como luta, pois ela também possui características para além do caráter combativo. Tal raciocínio entende a capoeira como uma prática que se metamorfoseia em outras.

Logo, qualquer tentativa de definição da capoeira exige a compreensão de seu caráter híbrido, pois a capoeira também pode ser dança, jogo, teatro, dentre outros. Essa capacidade de absorver e transformarse em diversas possibilidades de práticas corporais torna a capoeira um interessante tema, pois temos dentro de um mesmo contexto a possibilidade de mesclar propriedades da dança, jogo, luta, ginástica, esporte, ritmo, música, arte etc. Talvez tal característica da capoeira seja compreendida no interior do contexto de formação da nossa cultura: uma cultura híbrida que surge da mistura de diversas outras.

Por outro lado, a história nos mostra que o aspecto de embate da capoeira teve de ser disfarçado devido ao caráter repressor que a prática poderia sofrer, caso demonstrasse algum perigo:

Se a capoeira fosse apenas uma luta, ela seria muito mais vulnerável quando exercitada. Então, o próprio escravo para continuar sua prática, teve que dar a ela um caráter duplo. Porque quando o policial chegava numa roda de capoeira, vinha logo a

7-Vale a pena pensar nas técnicas corporais que podem concorrer em danos físicos sérios. No caso da capoeira, um bom mestre pode esperar anos de convívio para ensinar ou mesmo não ensinar a um aluno determinadas técnicas que podem ser usadas de maneira indevida. 
resposta: 'Não [seo] polícia, isso aqui é brincadeira, isso aqui é jogo'. (Depoimento de Carlos Eugênio Líbano Soares em: PASTINHA, 1998, dvd).

Nesse sentido, o corpo na capoeira caracteriza-se também pela dissimulação, pelo disfarce. Sua identidade perpassa a ideia de ambiguidade, absorve com facilidade outros códigos de outras técnicas corporais, camufla-se em dança, em jogo etc. Assim, é preciso propor corporalmente a dissimulação, o engano, pois os gestos da capoeira brincam com a noção de verdade. Jogar capoeira é disfarçar as intenções do corpo.

De fato, em um momento histórico em que a tirania é severa, é necessário esconder a própria vontade de sobrepujar o opressor. Talvez atualmente não seja mais necessário ao sujeito esconder sua força, pelo contrário, o interesse em demonstrar e mostrar suas virtudes é iminente atualmente na roda de capoeira. Talvez por isto, ensinar a dissimulação seja tão difícil.

Inversão corporal

O corpo na capoeira inverte uma lógica de se colocar: troca-se o alto pelo baixo, o ofensivo e o defensivo, a frente pelo traseiro, as mãos pelos pés... A capoeira impõe ao corpo posições que em outras situações poderiam ser consideradas como "esquisitices". Num certo sentido, para olhos alheios, a capoeira autoriza o corpo a ridicularizar-se, autoriza o erro e, mais do que isso, autoriza o riso sobre o próprio erro. E é aí que se aprende a acertar, a atacar e a se defender, disfarçando a luta e preparando as investidas... Assim, no processo pedagógico, é preciso experimentar corporalmente posições que normalmente não são cotidianas e nem convencionais.

\section{Musicalidade}

Na capoeira, a musicalidade é característica primordial. A música é como um fio condutor que faz a ligação entre todos os participantes da capoeira. É notório que a música interfere no desenvolvimento do jogo da capoeira. Determinados gestos e, principalmente, a intencionalidade desse gestual, surgem a partir de determinados ritmos. Corpo e música dialogam no processo de significação da capoeira. 
As palmas em ritmo coletivo ou o uso de alguns instrumentos específicos da capoeira podem ser usados nas aulas. Mesmo o berimbau, instrumento primordial na capoeira, pode ser aprendido com um pouco de dedicação e não há necessidade de ser um musicista ou um capoeirista experiente para tematizar alguns instrumentos no âmbito da formação de professores. Neste processo é preciso compreender que a relação entre música e capoeira incorpora o próprio reconhecimento de que a musicalidade da capoeira constitui um elemento ritual particular cuja rigorosidade exige parâmetros diferentes no espaço específico da formação de professores.

Diálogo Corporal

A capoeira não ocorre na sua plenitude no plano individual, é necessária a existência do outro, sem o qual não é possível jogar capoeira. Nesse sentido, se pensarmos na dependência do outro para continuidade do jogo, não há necessidade do jogo ser definitivo e nem competitivo.

Um diálogo pressupõe uma comunicação entre duas pessoas. $\mathrm{Na}$ capoeira, o corpo diz algo para outro que, ao ouvir, responde através de um repertório gestual que pode ser construído paulatinamente no contexto das aulas ${ }^{8}$. Na capoeira, esse diálogo se constrói entre os vários sujeitos que compõem a roda de capoeira, pois os dois corpos que dialogam durante o jogo dependem dos demais que os rodeiam. Assim, uma roda de capoeira é o momento de uma grande roda de conversa.

\section{Raiz Africana}

A capoeira possui princípios originários do processo de escravidão dos povos africanos. Seus sentidos e significados contêm o germe do legado dessa história. Na pedagogia africana, os ensinamentos são passados através da proximidade entre mestre e discípulo. Nesse sentido, o toque, o odor, o olhar e a atenção são voltados para o sujeito. Sabemos que não se trata de reproduzir a pedagogia mestre-discípulo no âmbito da formação de professores, mas é preciso reconhecer as particularidades desta pedagogia e buscar as raízes africanas da qual ad8-Para mais detalhes da capoeira como possibilidade de diálogo corporal, ver Santos (2009). 
vém a capoeira no processo de ensino e aprendizagem. Exemplos desta pedagogia aparecem no respeito ao mais velho, ao mais sábio, na proximidade entre os membros devido à predominância da transmissão oral dos saberes e à necessidade da confiança entre os membros do grupo e na a confecção artesanal dos instrumentos musicais.

Mandinga

A origem do termo mandinga é misteriosa, mas a sua associação ao universo mágico e misterioso da capoeira é indispensável. Segundo a enciclopédia livre Wikipédia (2009), o termo tem sua origem no Brasil colonial: designação dada ao grupo étnico de origem africana possuidor do hábito de carregar junto ao peito pequeno pedaço de couro com inscrições de trechos do alcorão, que negros de outras etnias denominavam patuá. Outras etnias viam nessa identificação entre si como um fenômeno mágico, atribuindo muitas vezes ao patuá poderes mágicos.

A mandinga expressa um sentido essencial no contexto da capoeira, algo que todo praticante reconhece como elemento fundamental desta prática:

Na capoeira, mais do que a força física, o mais importante é a malícia, a mandinga. A malícia é uma arma do jogo na qual o corpo não está só, mas é todo olhar, vísceras e idéias. Malícia para surpreender o adversário, que permite expô-lo ao ridículo, tirar-lhe a honra, que mais do que danos físicos, causa danos morais. Olhar que, fulminante, descobre no outro sua fragilidade: adivinha-lhe pensamento e movimento. Mandinga que é mágica, uma vez que estimula o desejo de querer adivinhar. (MORENO, 2003, p.61).

A questão que se coloca é que a mandinga se constitui em um saber que só pode ser identificado após a sua realização, portanto, parece não ser possível definir antecipadamente se algo é mandinga ou não. Então, se a mandinga não pode ser antecedida, como pode ser possível simulá-la em um processo de ensino e aprendizagem?

Alguns significados da capoeira parecem não atravessar determinadas fronteiras. No caso deste trabalho, cujos parâmetros se pautam na possibilidade de capturar os fenômenos através da escrita, não é possível apreender aspectos como o sentido e significado da mandinga, por 
exemplo. Por outro lado, isso nos remete a uma questão interessante do âmbito dos processos formais de aprendizado humano, ou seja, há conhecimentos que se aprende sem a intencionalidade de quem ensina.

\title{
Conclusão
}

O docente de Educação Física normalmente não é um mestre de capoeira, dessa forma irá mobilizar o conhecimento adquirido no seu curso de graduação ou o conhecimento adquirido em um grupo específico de capoeira para poder ensiná-la na escola. No entanto, uma das dificuldades de inserção da capoeira no âmbito escolar diz respeito à falta de segurança desses docentes em relação ao ensino de capoeira. Por isso, nossa tentativa é contribuir no processo de formação dos professores com uma perspectiva de apropriação de alguns de seus elementos para o ensino na escola. Cabe lembrar que outras ações de ensino, pesquisa e extensão precisariam também ocorrer no âmbito da formação superior para contribuir ainda mais na qualificação docente para outras ideias e possibilidades de intervenção no ensino, pesquisa e extensão (PALHARES, 2007; 2010; CAVALCANTE; PALHARES, 2008,).

\section{Capoeira in the training process of physical education teachers}

\begin{abstract}
The aim of this paper is to present some reflections regarding the inclusion of capoeira in the training of physical education teachers. Based on theoretical references, we looked to present some suggestions for the pedagogization process of capoeira. We consider that there is much to be done on the subject of incorporating capoeira within the area of physical education; hence our intent was to present some pedagogical reflections and suggestions that may contribute to this process.
\end{abstract}

Keywords: Capoeira - Teacher Training - Pedagogization

\section{La capoeira en la formación de profesores en educación física}

\section{Resumen}

Este artículo presenta algunas reflexiones acerca de la inclusión de la capoeira en la formación de profesores en educación física. Desde referencias teóricos del área buscamos presentar algunas sugerencias para el proceso metodológico de la capoeira. Se puede decir de lo mucho que es la integración de estos conocimientos en cursos de formación y desempeño profesional en educación física, total que, la principal intención há sido presentar algunas reflexiones e sugerencias pedagógicas 
que contribuyan en este proceso.

Palabras clave: Capoeira - Formación Profesional - Pedagogía de Capoeira

\section{Referências}

ABIB, P. R. J. Os velhos capoeiras ensinam pegando na mão. Caderno Cedes. Campinas, v.25, n.68, p.86-98, 2006.

ALVES JUNIOR, E. de D. Discutindo a violência nos esportes de lutas: a responsabilidade do professor de educação física na busca de novos significados para o uso das lutas como conteúdo pedagógico. In ENCONTRO REGIONAL DE HISTÓRIA, 12, 2006, Rio de Janeiro. Anais. Rio de Janeiro: ANPUH-RJ, 2006.

BETTI, M. O que a semiótica inspira ao ensino da Educação Física. Discorpo. São Paulo, n.3, p.25-45, 1994.

BRASIL. Ministério da Educação. Parâmetros Curriculares Nacionais. Educação Física, Brasília, 1998.

CAMPOS, H. J. B. C. Capoeira na universidade. Revista Baiana de Educação Física. Salvador, v.1, n.3, p.15-23, 2000.

CAVALCANTE, J. C. O.; PALHARES, L. R. A capoeira no processo de inclusão social. FIEP Bulletin. Foz do Iguaçu, v.78, special edition, p.107-110, 2008.

CERTEAU, M. de. A escrita da História. 2. ed. Rio de Janeiro: Fornese Universitária, 1982.

COLETIVO DE AUTORES. Metodologia do ensino de educação física. São Paulo: Cortez, 1992.

DARIDO, S. C.; RANGEL, I. C. A. (Orgs.). Educação física na escola: implicações para a prática pedagógica. Rio de Janeiro: Guanabara Koogan, 2005.

MESTRE BIMBA: a capoeira iluminada. GOULART, L. F., Rio de Janeiro, Lumen Produções e Co-Produção de Publytape, 2006, dvd.

JÚNIOR, L. C. V.; ABIB, P. R. J.; SOBRINHO, J. S. Capoeira e os di- 
versos aprendizados no espaço escolar. Revista Motrivivência. Santa Catarina, v.14, p.159-171, 2000.

MORENO. A. O Rio de Janeiro e o corpo do homem fluminense: o "não-lugar" da ginástica sueca. Revista Brasileira de Ciências do Esporte. Campinas, v.25, n.1, p.55-68, 2003.

PASTINHA: uma vida pela Capoeira. MURICY, A. C., Rio de Janeiro, Reccord Produções, 1998, dvd.

PAIVA, F. S. L. de. Jogando no Campo da Educação Física. In: CONGRESSO BRASILEIRO DE CIÊNCIAS DO ESPORTE / CONGRESSO INTERNACIONAL DE CIÊNCIAS DO ESPORTE, 14. 2005, Porto Alegre. Anais. Porto Alegre: CBCE, 2005.

PALHARES, L. R. Educação e cultura popular: inclusão social pela capoeira. Licere. Belo Horizonte, v.10, n.3, a4, 2007.

PALHARES, L. R. A capoeira e a licenciatura em Educação Física. In: SEMINÁRIO DE PESQUISA E PRÁTICA PEDAGÓGICA DA UFVJM, 1., 2010, Diamantina. Anais. Diamantina: UFVJM, 2010.

SANTOS, G. O. Da Capoeira e a Educação Física. 2005. 100 f. Dissertação (Mestrado em Educação) - Faculdade de Educação, Universidade Estadual de Campinas, Campinas, 2005.

SANTOS, G. O. Alguns sentidos e significados da capoeira, da linguagem corporal, da educação física... Revista Brasileira de Ciências do Esporte. Campinas, v.30, n.2, p.123-136, 2009.

SOUZA, S. A. R.; OLIVEIRA, A. A. B. Estruturação da capoeira como conteúdo da educação física no ensino fundamental e médio. Revista da Educação Física. Maringá, v.12, n.2, p.43-50, 2001.

WIKIPÉDIA. Desenvolvido pela Wikimedia Foundation. Disponível em: http://pt.wikipedia.org/wiki/Mandinga_(feiti\%C3\%A7o). Acesso em: 17 out. 2009.

Recebido em: 15/03/2010

Revisado em: 16/04/2010

Aprovado em: 14/09/2010 


\section{Endereço para correspondência}

leandro_palhares@yahoo.com.br

Leandro Ribeiro Palhares

Universidade Federal dos Vales do Jequitinhonha e Mucuri

Departamento de Educação Física.

Rua da Glória, 187

Centro

39100-000 - Diamantina, MG - Brasil 